\title{
AOR
}

Selected Papers of \#AolR2021:

The 22nd Annual Conference of the Association of Internet Researchers Virtual Event / 13-16 Oct 2021

\section{THE DYNAMICS OF DIGITAL MARKETS}

Anne Mette Thorhauge

University of Copenhagen

Jingyan Elaine Yuan

University of Illinois Chicago

Jacob Ørmen

University of Copenhagen

Andreas Gregersen

University of Copenhagen

Patrick Vonderau

Martin Luther University Halle-Wittenberg

The focus of this panel is the material, organizational, and cultural conditions of digital markets. Much research has been done on platform economies and platforms as a type of economic organization that contributes to reconfigurations of infrastructure, power, and the balance between public and private domains (Van Dijck, Poell, \& De Waal, 2018; Zuboff, 2019). Moreover, it has been pointed out that platform architectures shape market interactions in a number of ways (Srnicek, 2017). Nevertheless, the characteristics of these markets have not received the same amount of attention from the perspective of platform studies. While the notion of economy refers to the more general production, distribution and allocation in society, the idea of markets represents specific contexts of economic exchange typical of capitalist economies (Carruthers \& Babb, 2013). A more elaborate understanding of various markets and their relationships with digital platforms can expand our understanding of the economic implications that specific types of platform architectures can have at the level of economic interaction. Thus, the aim of this panel is to zoom in on how specific digital markets are shaped by types of platform architectures, how they are organized in practice, and the types of interactions they facilitate locally as well as globally. This involves studying the interplay between regulatory bodies and digital platforms, the technical design and operations of specific platforms, as well as the cultural conventions that develop among actors in the marketplace. 
The discussion takes as a starting point perspectives from economic sociology that emphasize how markets are embedded into broader social and societal structures (Granovetter, 2017) and conditioned upon cultural norms and conventions (Beckert, 2009). In addition, the panel is informed by the way economic sociology and STS has approached the material conditions of markets (Garcia-Parpet, 2007; MacKenzie, 2018) and the way these conditions frame and transform power relations and interaction patterns on specific markets. Lastly, the panel relies on approaches from media economics to understand the interplay between actors in the marketplace. By bringing these perspectives together, the panel presentations address different dynamics of digital markets.

The first paper shows how the gaming platform Steam orchestrates a market for trading digital commodities (skins) and in that process institutes its own virtual currency. This contribution highlights the key role that digital platforms play in enabling (and constraining) the formation of markets through technical infrastructures (most notably APIs) as well as legal frameworks. The second paper explores the relationship between platforms, markets, and state regulation. Using the Chinese e-commerce giant Alibaba as a case, the presentation shows how digital marketplaces in China developed in a regulatory vacuum as an interplay between platform business strategies, government initiatives, and cultural conventions of actors in the market. The third presentation shifts the perspective further towards culture to address the way market interactions are framed and conditioned upon cultural norms and conventions. It investigates the role of narratives, imagined futures, and collective action frames in motivating ordinary people to invest in the stock market (through retail investor apps like Robin Hood). The presentation looks at the recent investment hype around GameStop shares on the subreddit $r /$ WallStreetBets as an example of the dynamics involved. The fourth and last presentation explores how the online engagement industry is organized in practice and looks specifically at the phenomenon of "click farms". Through ethnographic field work, the author shows that far from being steered by top-down algorithmic governance, this digital economy consists of a multitude of actors that make everyday decisions based on pragmatic and local needs in their efforts make ends meet; in short, capitalizing from below.

Altogether, the presentations demonstrate that digital markets come in different forms and shapes, but also that they are guided, shaped, and constrained by similar mechanisms and practices.

\section{References}

Beckert, J. (2009). The social order of markets. Theory and Society, 38(3), 245-269. https://doi.org/10.1007/s11186-008-9082-0

Carruthers, B. G., \& Babb, S. L. (2013). Economy/society: Markets, meanings, and social structure (Second edi). Sage Publications.

Garcia-Parpet, M.-F. (2007). The social construction of a perfect market. In D. MacKenzie, F. Munesia, \& L. Siu (Eds.), Do Economists Make Markets?: On the Performativity of Economics (pp. 20-53). 
Granovetter, M. (2017). Society and economy. Harvard University Press.

MacKenzie, D. (2018). 'Making','taking'and the material political economy of algorithmic trading. Economy and Society, 47(4), 501-523.

Srnicek, N. (2017). Platform capitalism. John Wiley \& Sons.

Van Dijck, J., Poell, T., \& De Waal, M. (2018). The platform society: Public values in a connective world. Oxford University Press.

Zuboff, S. (2019). The age of surveillance capitalism: The fight for a human future at the new frontier of power. Profile Books.

\section{SKINBETTING, VIRTUAL MONEY AND THE MARKET STRATEGY OF THE STEAM PLATFORM}

Anne Mette Thorhauge, University of Copenhagen, Denmark

Skinbetting is one way gaming and gambling is currently converging on the internet. It refers to online game-settings where players can use skins as tokens in classic casino games such as Blackjack and Roulette as an alternative to cryptocurrencies or credit cards. This is possible because of Steam's API, which allows $3^{\text {rd }}$ party developers and websites to access the Steam community market: In contrast to competing platforms run by Epic or Electronic arts, Valve (the operator of Steam) has chosen to support a 'community market' on its platform where players can trade items from the games they play. While skins cannot be resold in Fortnite and player decks cannot be resold in FIFA, it is possible to resell items from games such as Counter-strike: Global Offensive, Dota 2, Team Fortress 2 and PUBG on the Steam platform where these games as played. Moreover, by way of its open API, Steam has also made this market accessible to $3^{\text {rd }}$ party developers (Thorhauge \& Nielsen, 2021). This has given way to a number of $3^{\text {rd }}$ party sites such as skin trading sites, which are perfectly legal, and skin betting sites, which are illegal to the extent that they are not authorized and offer their services to minors. On one hand, the existence of skinbetting may be an unfortunate consequence of Steam's 'secondary market strategy', on the other it may serve a number of economic aims such as growing the market, regulating prices, or supporting the transformation of skins into an alternative 'gamer-currency'. In this paper I will explore the last option. I will discuss money as a phenomenon and the role of institutions and technological infrastructures in the 'making of money'. In extension of this I will discuss how cryptocurrencies are currently challenging the way money is produced, how skins may or may not be seen as part of this tendency, and whether this can be seen as an aspect of Steam's market strategy.

With reference to Schumpeter, Ingham (Ingham, 2004) identifies two historical approaches to money: The commodity theory and the claim theory. From the perspective of the former money is basically just another type of commodity, which 
differs from other commodities due to its interchangeability. In contrast, the claim theory focuses on a more abstract notion of money as 'money of account', that is, money as a phenomenon that consists of claims and credits (Ibid, p. 21). It is by way of the latter that the phenomenon of 'credit-money' has become the most dominating form in late capitalism where the creation of money is directly tied to the creation of debt (Dodd, 2018). Given its crucial role in capitalist economies economic theory has paid surprisingly little attention to money as a theoretical concept. Indeed, much classic theory builds on the idea that money is a neutral commodity, a 'veil' that covers what can basically be boiled down to a barter economy (Samuelson 1974 cited in Ingham 2004). In doing so, economic theory fails to explain and take into consideration the way money is created and distributed in society. Ingham points out that power in societies not only relates to possession and quantities of money but also to who can produce money in the first place, with the state and the banking system as key institutions in question.

Thus, while we tend to believe that cryptocurrencies challenge our ideas about what money is, cryptocurrencies rather lay bare the inconsistencies and controversies that are built into different concepts of money. Bitcoin has thus been explained as commodity money without gold, fiat money without state and credit money without debt (Bjerg, 2016) and can in this way be defined through a double disintermediation in its separation from banks and the state (Dodd 2018). Technically this is done by replacing the authority of the state and the money lending power of the bank with the 'distributed ledger' made possible by blockchain technologies. This double disintermediation is tied to the 'tech-utopian' idea that bitcoin can remove politics from the production and management of money altogether (Dodd 2018, p. 8). However, as Dodd points out, this is contradictory in a number of ways. For the sake of the current argument the most important contradiction is that the seemingly 'horizontal' and distributed character of the blockchain system (which the tech-utopian perspective interprets as an emancipation from the power of the state and the banking system) in practice concentrates power in the code and the one who controls it. Indeed, the concentration of power can from this perspective be seen as greater than ever.

Returning to the question of skins and the Steam platform, what can this tell us about skins and their possible status as commodity and money? Firstly, skins from different game titles are currently being bought, collected, and gifted between players in a range of contexts depending on what is made possible by the specific platform architecture. In this way, skins represent a specific type of virtual commodity and at this level Steam does not differ significantly from other platforms and game titles that build their business models on microtransactions and the sales of virtual items. However, by featuring a secondary market strategy in the form of the steam community market, skins from specific Steam game titles can be traded between players for money, enhancing these skins' status as commodity as well as their fungibility into monetary value. And due to this fungibility skins figure next to credit cards and cryptocurrencies on various skinbetting sites. As mentioned in the introduction, this may just be an externality, an unfortunate consequence of Steams 'secondary market strategy' (Lehdonvirta \& Castronova, 2014). However, it may also serve specific strategic aims such as supporting the development of skins into a gamer-currency. From this perspective skinbetting may serve a symbolic as well as a performative purpose in Steams overall 
market strategy. Using skins as payment on skin-betting sites might be that crucial point where skins are transformed into commodity money, a currency independent of the state and the banking system. Unlike Bitcoin and other cryptocurrencies this currency is not upheld by a blockchain system, instead it is upheld by active gamers operating on the steam community markets which may just represent another path into the endeavor of making money, once the monopolies of the state and the banking systems have been broken.

\section{References}

Bjerg, O. (2016). How is bitcoin money? Theory, Culture \& Society, 33(1), 53-72.

Dodd, N. (2018). The social life of Bitcoin. Theory, Culture \& Society, 35(3), 35-56.

Ingham, G. (2004). The nature of money. Economic Sociology: European Electronic Newsletter, 5(2), 18-28.

Lehdonvirta, V., \& Castronova, E. (2014). Virtual economies: Design and analysis. MIT Press.

Thorhauge, A. M., \& Nielsen, R. K. L. (2021). Epic, Steam and the role of skin-betting in game (platform) economies. Consumer Culture, Forthcomin. 


\title{
ALIBABA'S BAZAAR: THE ECOLOGY OF PLATFORM ECONOMY IN CHINA
}

\author{
Elaine Yuan,
}

The focus of this study is how China's "platform economy" has evolved. Through a case study of Alibaba, China's leading e-commerce giant, this study argues that China's platform economy takes shape in situated interactions between the state actors and the private sectors. The evolving platform economy is a living social field. Its organizations, technologies, governance mechanisms, and market strategies, as suggested by Herrigel (2010), are consistently subject to mutual adjustment. This fluid process reconfigures the state-market and state-society relationships which in turn redefines the identities and boundaries of key actors.

The study focuses on three distinct empirical sites of interactions, which have also defined the different roles of Alibaba along the trajectory of its development in different social economic environments: as the vehicle of mass entrepreneur and consumption, the enabler of Taobao villages, and the alternative route of financialization. The study demonstrates that how the relationship between Alibaba and the state has evolved along time, from a largely laissez-faire stance of the state towards the digital private sector, to a symbiotic platform-state relationship, finally to a conflictual relationship in the new context of financialization.

The fast development of a digital economy is premised on the state's goal of postindustrial transformation and its related effort to develop digital infrastructures. The structural opportunity for China's digital platforms was further opened up during China's economic transition since the mid-2000s. Trying to readjust from an investment- and export-oriented growth model to a consumption-driven and service focused one, this economic structural reform is exemplified by the state's policy initiatives such as the "Internet +" and the mass entrepreneurship and innovation directives. It is seen as a way to solve China's long-term growth problem and to ease the tensions between sustained development and social equity in China.

Alibaba has positioned itself as a provider of self-employment opportunities for small business owners and grassroots entrepreneurs since its very beginning. This strategy fits well the state's economic goals of boosting domestic consumption and promoting the digital and service industries.

As the company further grows, Alibaba has deepened its ties to the government that is keen to boost domestic consumption and digital economy. With the urban markets increasingly saturated, Alibaba has strategically moved to grow in countryside. Its focus on rural villages helped restructuring relations between the state, capital, and local actors. Rural e-commerce became central in the state's strategic efforts of "newapproach to urbanization", "targeted poverty alleviation", and "rural revitalization" As Lin Zhang (2021) has observed, Alibaba helped the state advance its economic restructuring goals and mobilize local officials to participate in these efforts, thereby emerging as a private subcontractor for the state. 
After establishing its monopoly in e-commerce, Alibaba expanded further into finance sector with the establishment of Ant Group in 2014. Ant's financial enterprise started in 2003, when Alibaba debuted Alipay, a third-party payment service. Growing fast along Alibaba's e-commerce empire, Alipay nevertheless operated in the gray areas of China's otherwise tightly controlled financial sector.

Then came China's post-2008 economic transition. It opened up new space for private fintech companies to break into the state-monopolized financial industry. Alibaba's growth in the financial sector played well along the state's priorities along the lines of mass innovation and entrepreneurship. The idea of "inclusive finance" is poised to support rural areas and small businesses traditionally underserved by the big banks. Alibaba subsequently took the opportunity to further expand. It launched Yu'ebao, an investment service that allows users to invest their money through Alibaba directly, in 2013' Huabei, a consumer loan business, in 2014, and Jiebei, a microloan service, in 2015 (Zhang, 2020).

Alibaba's enormous user base and rich consumer data gave Ant a great advantage in the nascent fintech market, further encroaching on the turf of the state's banking institutions. As Alibaba's role in the finance sector grew, government regulators became more cautious and interventionist. Furthermore, the state embarked on a nationwide campaign to contain financial risks after the burst of the equity bubble in July 2015 and the fall of the peer-to-peer lending sector after 2016. Ant, particularly its profitable consumer credit and company loan services, came in for mounting regulatory scrutiny (Zhang, 2020).

The blurred lines between traditional banking and financial sectors and digital tech industries, as well as the murky role of the state as both a stakeholder and a regulator, pose challenges to existing legal and regulatory regimes of platform economy. More than any single economic sector or institution, digital economy, as exemplified by Alibaba's business empire, grows out of the situated interplays between the state and private sectors. These sites become places where actors define their selfunderstandings and interrelations.

\section{References}

Herrigel, G. (2010). Manufacturing possibilities: Creative action and industrial recomposition in the United States, Germany, and Japan (pp. 32-33). New York: Oxford.

Zhang, L. (2021). The labor of reinvention entrepreneurialism and the remaking of China after 2008. Book manuscript.

Zhang, L. (2020). Put Ant under the microscope. Six Tones. https://www.sixthtone.com/news/1006422/putting-ant-under-the-microscope 


\title{
DIAMOND HANDS TO THE MOON: COGNITIVE METAPHORS, COLLECTIVE ACTION FRAMES, AND INTERMEDIA PROCESSES RELATED TO R/WALLSTREETBETS
}

\author{
Jacob Ørmen and Andreas Gregersen, University of Copenhagen, Denmark
}

When stock market shares of brick-and-mortar video game store GameStop (GME) exploded in value during January 2021 (rising more than $2000 \%$ in a month), a large group of retail investors made millions of dollars in profit and inflicted billions of dollars in losses upon institutional investors. This extraordinary event was largely (but not solely) due to the coordinated activities of a collective of individuals which frequents the Reddit subforum $r$ WallStreetBets (WSB).

Our presentation outlines a study of the dynamics surrounding the WSB/GME case in Winter and Spring 2021. We build an analytical framework which synthesizes parts from four lines of work. The first is the narrative economics of Robert Shiller (2019), which emphasizes the role and structure of narratives in economics in general. The second is the economic sociology of Jens Beckert (2016), from which we borrow the central notion of fictional expectations, including the ideas that such expectations can be managed and that this management has intrinsic connections to power. The third part is the frame analysis of Gamson (1992) and Benford and Snow (2000), which delivers necessary finer grain on the formal nature of the representations; the most important component here is the existence of particularly powerful framing devices for collective mobilization. The fourth and final part of the framework is the notion of intermedia agenda-setting (McCombs, 2004; Neuman et al., 2014), where different media agendas feed into and out of each other over time.

Starting with the notion of economic narratives, Shiller (2019) emphasizes the role of representations and emotional reactions in the economy. Shiller proposes that we should look for constellations of narratives since several narratives typically are in play simultaneously. Our analysis of WSB/GME shows that WSB had, prior to the time of the viral GME event, already established a discursive repertoire consisting of a small set of communicative units.

This discursive repertoire has a distinct layered structure. The first and most basic layer consists of micro-units akin to memes, which function both as individually salient cognitive schemas and scaffolding of idio-cultural identity (Fine, 2012; Brekhus, 2015). Two of the most prominent and GME-relevant examples of cognitive schematic structures would be the micro-unit "Diamond Hands" (a popular meme on WSB meaning "to hold a risky stock instead of selling it") which signals strength and fortitude in individual agency - the opposite unit is "Toilet Paper Hands", and the contrast between immaculate beauty and vehicle for excrement is noteworthy in addition to the material implications. Another micro-unit is "Rocket to the Moon" (a meme signalling "the possibility of stocks rising dramatically"), where a technological-utopian and nostalgic/fantastic element evokes fantasies of space-age exploration. When these two memes are combined, this becomes a micro-narrative of economic expectations (Beckert, 2016), signifying that community members can prosper by holding a specific 
stock. The labels "retards" and "autistics" are examples of identity-scaffolding meme units. Both of these labels function as idio-cultural honorifics are used to praise community members for consciously engaging in highly speculative and risky financial activities.

Two additional points from Shiller are relevant here. First, the power of economic narratives tends to increase when they incorporate celebrities as a kind of human angle into an otherwise faceless and dry economic narrative. The WSB/GME narrative constellation includes at least two celebrities who were recruited into the narrative as heroes/spokespersons, namely Michael Burry (activist investor) and Elon Musk (worldfamous entrepreneur) - the latter invoking his own status as privy to the game through Twitter. WSB also has its own proto-celebrity in the guise of member DFV, who ostensibly spearheaded the GME event on the subreddit itself. The second point from Shiller is that economic narratives need not make sense on a mechanistic level, i.e. they do not need to explain how the stock market works, they merely need to evoke positive feelings and fantasies of profit. GME offers an example of this being both true and in need of qualification. A narrative construction such as "Diamond hands" + "Rocket to the moon" is obviously purely metaphorical, but the GME event also involved more technical explanations of how collective action of holding stocks might trigger a socalled short squeeze. This way, the overall constellation of narratives offers both metaphorical power and a mechanistic explanation. It also shows how fictional expectations can be managed by savvy actors, in this case by explaining in some detail how Diamond Hands may trigger an actually existing stock-market mechanism.

The resulting mass mobilization of WSB to buy and hold GME was scaffolded by an additional layer of representation, namely a set of collective action frames (Benford \& Snow, 2000) which integrated the memetic units and drew on the rebellious aura of Burry and Musk. The dominant frame drew heavily on notions of injustice (Gamson, 1992) to deliver a morally convincing story of why and how "Diamond Hands on GME" could be a way to collectively "Stick it to The Man". This framing pitted the ragged and just retards, i.e. WSB retail investors, against evil Wall Street hedge funds such as Melvin Capital. This frame drew on existing cultural templates such as Strength in Numbers, David vs Goliath, Robin Hood vs illegitimate power etc.

In addition to this mix of idiosyncratic and more widespread discursive units, the WSB/GME process hinged upon a complex, recursive intermedia agenda-setting and framing process (McCombs, 2004; Neuman et al., 2014). This was not solely a process where established media relayed the communication from Reddit, but also a process of the financial markets reacting to the developing situation. This resulted in further media proliferation across Twitter as well as online news outlets, which led to massive exposure of Reddit and a wave of new Redditors (participants on the forum) joining the discussion and investing in hyped stocks (including but not limited to GME) through retail investing apps such as Robin Hood.

In summary, the presentation demonstrates how a perspective that synthesizes insights from cognitive social science, narrative economics, economic sociology, and media and communication theory is necessary to understand stock-market dynamics. 


\section{References}

Beckert, Jens. 2016. Imagined Futures: Fictional Expectations and Capitalist Dynamics. Cambridge, MA: Harvard University Press.

Benford, Robert D., and David A. Snow. 2000. "Framing Processes and Social Movements: An Overview and Assessment." Annual Review of Sociology 26:611-39.

Brekhus, Wayne H. 2015. Culture and Cognition. Cambridge: Polity.

Fine, Gary Alan. 2012. Tiny Publics. New York, NY: Russel Sage Foundation.

Gamson, William. 1992. Talking Politics. Cambridge: Cambridge University Press.

McCombs, Maxwell. 2014. Setting the Agenda: The Mass Media and Public Opinion. 2nd ed. Cambridge, UK: Polity Press.

Neuman, W. Russell, Lauren Guggenheim, S. Mo Jang, and Soo Young Bae. 2014. "The Dynamics of Public Attention: Agenda-Setting Theory Meets Big Data." Journal of Communication 64(2):193-214.

Shiller, R. J. (2019). Narrative Economics: How Stories Go Viral \& Drive Major Economic Events. Princeton University Press. 


\title{
CAPITALIZING FROM BELOW: AN ETHNOGRAPHY OF 'CLICK FARMING'
}

\author{
Patrick Vonderau, Martin Luther University Halle-Wittenberg, Germany
}

Markets are like the dark matter of digital media culture: they are felt everywhere as densely structured and coordinated cultural forms, yet tend to remain largely out of sight. One reason for this strange co-occurrence of omnipresence and apparent invisibility (where exactly are songs, movies or books traded online?) is that media themselves are partly "hidden organizations" (Costas \& Grey 2016), at least from a consumer perspective. Substantial parts of value creation are deliberately hidden from view because of business secrecy related to sunk costs in research and development, for instance, or because value is extracted from data without user consent, as in the case of private data brokerage (Draper 2019). Another reason is that a considerable part of market exchange involves "organizing without organizations" (Czarniawska 2014): it doesn't necessarily require a formal setting to sell games or even production services online. This paper focusses on yet another reason, which is that some digital media markets are organized in ways that only allow to infer how something has been exchanged, even for market actors themselves. In these cases, it is the market structure itself which obscures how exchange takes place, regularly prompting attempts to attribute accountability to someone: who is in charge of this specific market? More specifically, this paper looks at the ways how engagement with social media and cultural content is commodified and traded by actors that partly belong to formal and legit, even branded organizations, and that partly are anonymous and unknown. While previous research on this online engagement industry has worked with notions of disinformation, shadow or "fake" economies (e.g. Abidin 2018; Ong \& Cabanes 2019), the research presented here is premised on the observation that there is no false representation of value at stake in markets for likes, followers or plays, and that these markets are not even necessarily informal or illicit. Putting a praxeological bend to the idea informing this panel, i.e. of markets being fields (Fligstein 2012), this paper studies various market practices that are required to "capitalize" on something as elusive as a like (Muniesa et al. 2017; Kjellberg \& Helgesson 2007).

What does it mean "to like" something in the context of this engagement industry? How is the market for likes (but also: followers, comments or plays) put into practice?

Technically, the like is a Facebook plugin introduced in 2009 with a button and counter. Culturally, liking is a numerical practice that emulates social connectivity; likes count because of this purpose of premediating connectivity (Gerlitz \& Helmond 2013). Anticipating more likes or connections, the receiver of a like imagines, rather than rationally calculates, the prospects of a near future. While there are several reasons why engagement is bought and sold, the underlying economic logic of this industry remains bound to a concept of imagined futures as discussed in economic theory since the $19^{\text {th }}$ century (Beckert 2016; Stäheli 2013). A main contention of this paper is that in order to understand this industry, it is helpful to map its distributed "system of provision" (Fine 2002) and its economic logics rather than attributing accountability to isolated industry stakeholders, as journalists and regulators do (e.g. Confessore et al. 2018). 
How selling likes, followers or plays is done practically amounts to what I would like to describe as capitalizing from below. Not in the sense of 'the people' vs. 'the system,' as often invoked in investigative reports that locate "click farms" in the Global South, but to nuance the wide-spread idea of top-down algorithmic governance or logics (Gillespie 2014; Nieborg \& Poell 2018). What we have found is that markets for engagement are neither a direct function of North-South hierarchies nor of automation, as bots are only one among several prominent ways to generate engagement globally. Analyzing market practices, this paper rather highlights a temporal logics that is also very much local and situational (Rofel \& Yanagisako 2019). Based on an extensive, three-year research project that aimed to map the global topology of the engagement industry, the paper follows one single chain of supply chain actors from Germany to Russia and beyond in order to find out, through an unravelling of their vast "action nets" (Czarniawska 2011), how agents of capitalization think, act, and perform this digital market. The paper combines forms of ethnographic fieldwork including interviews and (non-) participant observation with media industry analysis, and integrates an experimental collaboration with two investigative journalists and a criminologist in order to map a fascinating service economy.

This way, I also hope to contribute to, and complement, a broader discussion in Internet Studies which has mostly centered on platforms and platform architectures to explain the digital economy (Helmond 2015; Nieborg/Poell 2018). To do so, I am taking my cue from STS-oriented approaches within economic sociology, the anthropology of markets (e.g. Caliskan 2010), and a long tradition of cultural studies-oriented work in media studies now labelled as "production studies" (e.g. Caldwell 2008; see also Ong/Cabanes 2019 for a related move into the same direction).

\section{References}

Abidin, Crystal. 2018. Internet Celebrity: Understanding Fame Online. Bingley: Emerald.

Beckert, Jens. 2016. Imagined Futures: Fictional Expectations and Capitalist Dynamics. Cambridge, MA: Harvard University Press.

Caldwell, John Thornton (2008): Production Culture. Industrial Reflexivity and Critical Practice in Film and Television. Durham.

Caliskan, Koray. 2010. Market Threads: How Cotton Farmers and Traders Create a Global Commodity. Princeton: Princeton University Press.

Confessore, Nicholas et al. "The Follower Factory," The New York Times, January 27, 2018.

Costas, Jana, Christopher Grey. 2016. Secrecy at Work: The Hidden Architecture of Organizational Life. Stanford: Stanford University Press.

Czarniawska, Barbara. 2011. "Going Back to Go Forward: On Studying Organizing in Action Nets." In: Hernes, T, Maitlis S (eds.) Process, Sensemaking, and Organizing. Oxford: Oxford University Press, 140-160. 
Czarniawska, Barbara. 2014. A Theory of Organizing. Second Edition. Cheltenham: Elgar.

Draper, Nora. 2019. The Identity Trade. Selling Privacy and Reputation Online. New York: New York University Press.

Fine, Ben. 2002. The World of Consumption: The Material and Cultural Revisited. London: Routledge.

Fligstein, Neil, Doug McAdam. 2012. A Theory of Fields. Oxford: Oxford University Press.

Gerlitz, Carolin, and Anne Helmond. 2013. "The Like Economy-Social Buttons and the Data Intensive Web." New Media \& Society 15 (8): 1348-65.

Gillespie, Tarleton. 2014. The relevance of algorithms. In: Gillespie T, Boczkowski PJ and Foot KA (eds.) Media Technologies: Essays on Communication, Materiality, and Society. Cambridge, MA: The MIT Press, pp. 167-194.

Helmond, Anne. 2015. "The Platformization of the Web: Making Web Data Platform Ready." Social Media + Society 1(2): 1-11.

Kjellberg, Hans, and Claes-Fredrik Helgesson. 2007. "On the Nature of Markets and Their Practices." Marketing Theory 7 (2): 137-62.

Muniesa, Fabian et al. 2017. Capitalization: A Cultural Guide. Paris: Presses des Mines.

Nieborg, David, and Thomas Poell. 2018. "The Platformization of Cultural Production: Theorizing the Contingent Cultural Commodity." New Media \& Society 20 (11): 427592.

Rofel, Lisa, Sylvia. J. Yanagisako. 2019. Fabricating Transnational Capitalism. Durham: Duke University Press.

Ong, Jonathan Corpus, Jason Cabanes. 2019. "When Disinformation Studies Meets Production Studies: Social Identities and Moral Justifications in the Political Trolling Industry." International Journal of Communication 13 (2019): 5771-5790.

Stäheli, Urs. 2013. Spectacular Speculation: Thrills, the Economy, and Popular Discourse. Stanford: Stanford University Press. 